\title{
Genetic variation and covariation for resistance and tolerance to Cucumber mosaic virus in Mimulus guttatus (Phrymaceae): a test for costs and constraints
}

\author{
DE Carr ${ }^{1}$, JF Murphy ${ }^{2}$ and MD Eubanks ${ }^{2}$ \\ ${ }^{1}$ Blandy Experimental Farm, University of Virginia, 400 Blandy Farm Lane, Boyce, VA 22620, USA; ${ }^{2}$ Department of Entomology \\ and Plant Pathology, 301 Funchess Hall, Auburn University, Auburn, AL 36849, USA
}

\begin{abstract}
Genetic variation for resistance and tolerance to pathogens may be maintained by costs represented as genetic tradeoffs between these traits and fitness. The evolution of resistance and tolerance also may be constrained by negative genetic correlations between these defense systems. Using a complete diallel, we measured genetic variation and covariation for and among performance, resistance, and tolerance traits in Mimulus guttatus challenged with a generalist pathogen, Cucumber mosaic virus (CMV). Viral coat protein was detected by enzyme-linked immunosorbent assay (ELISA) in all inoculated plants, indicating that all plants were susceptible to infection, although the ELISA absorbance varied quantitatively across plants. Plants inoculated with CMV had significantly reduced aboveground biomass and flower production relative to controls, although date of first flower was unaffected by
\end{abstract}

infection. All three of these performance traits showed moderate to high narrow-sense heritability $\left(h^{2}=0.32-0.62\right)$ in both inoculated and control plants. We found phenotypic variation for both tolerance of and resistance to our strain of CMV, but both displayed very low narrow-sense heritability $\left(h^{2}<0.03\right)$. We found no evidence of a trade-off between resistance and tolerance. We also found no evidence for a cost of resistance or tolerance. In fact, a significant genetic correlation suggested that plants that were large when healthy had the greatest tolerance when infected. Significant, positive genetic correlations found between performance of uninfected and infected plants suggested that selection would likely favor the same $M$. guttatus genotypes whether CMV is present or not.

Heredity (2006) 96, 29-38. doi:10.1038/sj.hdy.6800743; published online 28 September 2005

Keywords: Cucumber mosaic virus; genetic correlation; maternal effects; Mimulus guttatus; resistance; tolerance

\section{Introduction}

Genetic variation for resistance and tolerance to pathogens has been demonstrated in natural populations in a number of plant-pathogen systems (eg Jarosz and Burdon, 1991; Schmid, 1994; Biere and Antonovics, 1996; Mitchell-Olds, 1996; Morrison, 1996; Chiang et al, 2002; Kover and Schaal, 2002; Liu and Ekramoddoullah, 2003). Such variation is undoubtedly important in the evolution of these defenses (Gilbert, 2002), and this likely plays an important role in the spatial and temporal dynamics of both plant and pathogen populations (Thrall and Burdon, 2000). Genetic variation for disease resistance and tolerance can be maintained by frequencydependent selection (Hamilton et al, 1990; Roy and Kirchner, 2000) and by trade-offs. These trade-offs can be in the form of a fitness cost (Frank, 1992, 1994; Antonovics and Thrall, 1994) or trade-offs between different systems of defense (Tiffin, 2000; Eubanks et al, 2004). This study takes a quantitative genetic approach to

Correspondence: DE Carr, Blandy Experimental Farm, University of Virginia, 400 Blandy Farm Lane, Boyce, VA 22620, USA.

E-mail: dec5z@virginia.edu

Received 12 November 2004; accepted 22 July 2005; published online 28 September 2005 understanding genetic variation and the factors that might maintain this variation for resistance and tolerance to a generalist viral pathogen.

As resistance to pathogens likely requires the mobilization of limited resources, resistance is widely believed to be an expensive strategy for a would-be host plant (Sheldon and Verhulst, 1996). The cost of resistance would manifest itself in the reduced fitness of resistant plants relative to susceptible plants when the pathogen is not present. As a result, we expect negative genetic correlations between measures of resistance and the fitness of healthy plants. These costs can help maintain genetic variation for resistance if the environment is spatially or temporally heterogeneous for the presence or severity of the pathogen (Antonovics and Thrall, 1994).

Plants also vary in the degree to which they can tolerate given levels of infection. Genetic variation for tolerance could also be maintained by a cost (Simms and Triplett, 1994; Mauricio et al, 1997). Theoretical considerations of herbivory and disease suggest that selection may generate trade-offs between tolerance and resistance (van der Meijden et al, 1988; Simms and Triplett, 1994; Fineblum and Rausher, 1995, 2002; Stowe, 1998; Strauss and Agrawal, 1999; Tiffin, 2000; but see Restif and Koella, 2004). As resistant genotypes should experience less damage, selection for the ability of these 
genotypes to tolerate damage would likely be weak. In less resistant, more heavily damaged plants, there would likely be strong selection for tolerance. As a consequence, we expect to observe a negative genetic correlation between resistance and tolerance.

The ecology and evolution of plant-pathogen interactions in noncrop species has been best studied in plantfungus systems. In particular, work on Linum marginale and its rust pathogen, Melampsora lini (eg Jarosz and Burdon, 1991; Thrall et al, 2001), and studies of Silene alba and its anther smut fungus, Microbotryum violaceum (eg Alexander and Antonovics, 1995; Ouborg et al, 2000), have greatly advanced the field. Studies in noncrop plant populations of bacterial pathogens (eg Kover and Schaal, 2002) are much rarer. Although there are many surveys of wild reservoirs of viral pathogens that infect economically important plants, the evolution and ecology of these wild plant-pathogen interactions have rarely been studied (Gilbert, 2002). Given the wide variety of genetic systems associated with plant defenses against the diversity of pathogens (Ellis et al, 2000), broadening the field to include the interactions between viruses and wild hosts seems essential (Harper, 1977; Fraser, 1990).

Most studies of resistance and tolerance in plants drawn from natural populations have relied on broadsense heritabilities and broad-sense genetic correlations (eg Biere and Antonovics, 1996; Davelos et al, 1996; Morrison, 1996; Koskela et al, 2002). Although these studies have made important contributions to our understanding of variation in defenses against pathogens, there are limits to their interpretation. Broad-sense heritabilities confound the contributions of additive genetic variation, nonadditive genetic variation (dominance and epistasis), and maternal effects (Falconer and MacKay, 1996; Lynch and Walsh, 1998), making definitive tests of trade-off hypotheses elusive. This could result in both quantitative and qualitative errors in estimates of variation and covariation. Crossclassified breeding designs, such as the diallel design employed in this study, are exceptionally powerful tools for differentiating among the various causal components of phenotypic variation, providing less ambiguous tests of the cost and trade-off hypotheses as well as providing important insight into the nature of variation for resistance and tolerance.

This study examines genetic variation and covariation for resistance and tolerance in the herbaceous annual, Mimulus guttatus, to the widespread, generalist pathogen, Cucumber mosaic virus (CMV). We used a complete diallel crossing design in order to separate additive and nonadditive genetic effects from maternal, paternal, and random environmental effects. We address the following questions: (1) What are the levels of genetic and environmental variation for resistance and tolerance to CMV in this population of M. guttatus? (2) Is there evidence of a cost to resistance or tolerance? and (3) Is there evidence of a trade-off between resistance and tolerance?

\section{Methods}

\section{Study species}

M. guttatus DC (Phrymaceae, formerly Scrophulariaceae; Beardsley and Olmstead, 2002) ranges throughout western North America from Mexico to Alaska, occupy- ing a variety of wet, open habitats. Estimates of outcrossing rates from different populations vary from about $75 \%$ selfing $(t=0.25)$ to complete outcrossing $(t=1.0)$, averaging about $t \approx 0.60$ (Ritland and Ritland, 1989; Ritland, 1990; Dudash and Ritland, 1991; Willis, 1993). It is capable of producing 100 or more large ( 20$30 \mathrm{~mm}$ wide), yellow, hermaphroditic flowers, each capable of producing several hundred seeds. Most $M$. guttatus populations are annual, but in habitats that are wet year-round, it can be perennial, spreading through rhizomes (Dole, 1992).

We collected seed for the parental generation in this experiment in June 1997 from an annual M. guttatus population in Santa Clara County, CA, USA $\left(37^{\circ} 17^{\prime} \mathrm{N}\right.$, $\left.122^{\circ} 09^{\prime} \mathrm{W}\right)$. This population (M5) has been used in previous studies on the effect of inbreeding on interactions between M. guttatus and both CMV (Carr et al, 2003; Eubanks et al, 2004) and the spittlebug Philaenus spumarius (Carr and Eubanks, 2002).

CMV has one of the broadest host ranges among viruses that infect plants (Palukaitis et al, 1992), infecting up to 1241 crop and noncrop species in 101 plant families (Edwardson and Christie, 1991) including plants within the Scrophulariaceae (Brunt et al, 1996). The ubiquitous nature of CMV results, in part, from its ability to be transmitted by at least 75 species of aphid in a nonpersistent manner (Palukaitis et al, 1992). Aphids acquire CMV during brief probes of infected epidermal cells while attempting to determine if the plant is a suitable host, and with no latent period, can inoculate the virus during a similar test feed on a neighboring plant.

Upon entering a living cell, the CMV infection process is initiated by the production of viral-encoded proteins and replication of the viral RNA. Three genomic, messenger-sense RNA species, each packaged in its own particle, are required for a complete systemic infection, that is, replication, cell-to-cell, and phloemdependent movement (Palukaitis et al, 1992). During the cell-to-cell movement process, CMV moves via plasmodesmata. The virus will eventually move into vascular tissues, particularly phloem, through which it is rapidly transported to tissues that act as sinks for photoassimilates. This phloem-dependent movement process typically results in the entry of CMV into the roots, young developing tissues, and reproductive organs (Palukaitis et al, 1992). The systemic invasion produces the dramatic symptoms observed in most hosts, such as chlorosis, mosaic, blistering, and deformation of leaves. While the severity of these symptoms may vary with host, virus strain, and environmental conditions, a general stunting of plant growth resulting from a lack of extension of internodes is common. For many plants, systemic infection by CMV simulates or perhaps triggers early senescence.

Resistance to viral infection can occur at any of the three stages of infection described above. Extreme resistance occurs in those interactions in which the plant does not allow detectable amounts of viral accumulation within individual inoculated cells (Murphy et al, 1998). Resistance may restrict virus movement from one cell to the next, resulting in localization of the virus or allow movement within but not out of the inoculated leaf (Dawson and Hilf, 1992; Hull, 2002; Ponz and Bruening, 1986). A more common expression of resistance limits the 
extent of systemic invasion of distant tissues (Murphy and Kyle, 1995; Guerini and Murphy, 1999).

\section{Diallel crossing design}

On 26 September 2000, 30 field-collected M. guttatus seeds from 13 maternal families were sown into square 72- $\mathrm{mm}^{2}$ pots containing Wetsel Growing Medium III in the greenhouse at the Blandy Experimental Farm in Boyce, VA, USA. On 13 October 2000, a single seedling from each maternal family was transplanted into its own $72-\mathrm{mm}^{2}$ pot. Pots were bottom-watered throughout the crossing period, and sodium vapor lights were used to extend the photoperiod to 18L:6D. From 29 November to 7 February 2001, controlled crosses were performed on these 13 plants. Each plant served as a pollen donor to and a pollen recipient from each of the other 12 such that all 156 possible maternal-paternal combinations (excluding self-pollinations) of these 13 plants were generated. These 156 crosses produced 78 genetically full-sib families, with reciprocal maternal and paternal families of each. Flowers were emasculated in-bud 1 day prior to all hand-pollinations. Hand-pollinations were accomplished by holding an anther from the pollen donor with a fine forceps and smearing pollen from the anther onto the receptive surface of the stigma. Hand-pollinations typically yielded several hundred seed. The diallel assumes that traits have a polygenic basis and that there is no inbreeding in either the parents or offspring.

\section{Diallel experiment}

On 14 September 2001, 30 seeds from each of the 156 families were sown as described above. From 1 to 3 October, 12 randomly selected seedlings from each were transplanted into their own $72-\mathrm{mm}^{2}$ pots. Two seedlings from each of the 156 families were randomly assigned to each of six blocks. A block consisted of a single $1.5 \times 3.65 \mathrm{~m}$ greenhouse bench, and the 338 pots of each block were spread out on the bench top as much as possible to minimize the plant-to-plant contact. On each bench, the pots sat within one of twelve $86 \times 40 \mathrm{~cm}$ plastic trays to allow bottom watering of plants. Each tray could accommodate 44 pots. A $400 \mathrm{~W}$ sodium vapor light above each table extended the photoperiod to 18L:6D as needed.

In each block, one member of each of the 156 sib pairs was randomly assigned to the virus inoculation treatment, and the other was assigned to the mock-inoculated control treatment. Virus inoculations took place on 20 October when the seedlings had grown into large rosettes. The well-characterized CMV strain Fny (kindly provided by Peter Palukautis, Scottish Crop Research Institute, Invergowrie, Scotland) was used. The largest two leaves on each rosette were lightly dusted with carborundum to serve as a minor abrasive (this creates nonlethal wounds that allow entry of viral particles into epidermal cells) followed by mechanical (rub) inoculation with CMV inoculum. The CMV inoculum consisted of systemically infected Nicotiana tabacum cultivar Kentucky 14 tissue ground in $50 \mathrm{mM}$ potassium phosphate buffer, $\mathrm{pH} 7.0,10 \mathrm{mM}$ sodium sulfite $(1 \mathrm{~g}$ tissue: $10 \mathrm{ml}$ buffer). CMV accumulates to high levels in Kentucky 14, and we have found it to be a reliable source of inoculum for M. guttatus. Mock-inoculated control plants (hereafter referred to simply as 'control' plants) were inoculated in a similar manner but with healthy Kentucky 14 tissue ground in buffer. Plants were inoculated by block, with fresh inoculum used for each block.

All plants were monitored daily, and date of first flower (DFF) and symptoms of CMV infection (chlorosis, curled leaves, malformed flowers, and stunted growth) were noted for each. Plants were harvested by block from 26 November to 8 December. At the time of harvest, all flowers and calyces were counted to determine total flower production. In order to assay each plant for CMV (see below), we collected a single leaf from the node above the basal (inoculated) leaves. Each leaf was placed in a sterile Whirl Pak ${ }^{\mathbb{R}}$ sample bag and stored at $5^{\circ} \mathrm{C}$. Plants were then cut at soil level, placed in paper bags, and dried to a constant weight at $50^{\circ} \mathrm{C}$. We determined aboveground biomass with an Ohaus Precision Standard top-loading balance.

We defined tolerance to the CMV pathogen as the performance difference between an infected host and an uninfected host. Performance was measured as flower production and aboveground biomass, and these data were $\log$ and square-root transformed, respectively, to normalize the data. We estimated tolerance by subtracting the performance of a control plant from the performance of its inoculated full sib from the same experimental block. Negative values of tolerance represent decreased performance of infected plants, while positive values suggest overcompensation. Owing to the transformations, this definition is analogous to the 'proportional fitness' definition of tolerance to herbivory provided by Strauss and Agrawal (1999) and not the 'absolute difference.' We preferred a proportional measure in order to account for absolute differences among families.

The performance of CMV within its host plant can be taken as an operational measure of host resistance. To measure virus accumulation in leaf tissues of M. guttatus, direct double antibody sandwich enzyme-linked immunosorbent assay (ELISA) was carried out at Auburn University. A CMV-specific ELISA kit was used according to the manufacturer's instructions (Agdia Inc., Elkhart, IN, USA). A single disk of $7.5 \mathrm{~mm}$ in diameter was removed from each leaf using a cork borer and homogenized in $150 \mu \mathrm{l}$ of extraction buffer (prepared as recommended by Adgia Inc.) using a Teflon homogenizer in an eppendorf tube. ELISA reactions (absorbance) were recorded at $405 \mathrm{~nm}$ with a Sunrise microtiter plate reader (Phenix Research Products, Hayward, CA, USA). In an effort to standardize ELISA reactions among tests that were performed at different times, each microtiter plate included a sample of purified CMV of known concentration. The ELISA reactions for each microtiter plate were recorded when the ELISA absorbance for the purified CMV reached 1.0. We also assayed 150 control plants. None of these exhibited any reactivity.

\section{Diallel analysis}

Genetic variance and covariance components were estimated using a restricted maximum-likelihood approach. This approach constrains all variance estimates to be 0 or positive. Estimates were generated using the Quercus program developed by Shaw and Shaw (1994), which follows the Cockerham and Weir (1977) 'Bio' genetic model for diallel analysis. Included in the model 
are the following six variance components: additive and dominance genetic effects, maternal and paternal non-nuclear genetic and environmental effects, an interaction component consisting of nuclear $\times$ non-nuclear interactions, and a random environmental component (nuclear $\times$ nuclear epistatic interactions are not estimable and assumed to be zero in Quercus). Separate univariate analyses were run for control and inoculated plants on each of three plant performance characters: DFF (calculated as the number of days post-transplant), total flower production (square-root transformed to meet homogeneity of variance and normality assumptions), and aboveground biomass (log-transformed to meet assumptions). To measure genetic variation for resistance, we ran a univariate analysis of ELISA absorbance from inoculated plants. Finally, variance components for tolerance were estimated separately for two measures of plant performance: flower production and aboveground biomass. Analyses involving tolerance based on DFF were omitted because we found no significant effect of virus infection on DFF (see Results below).

We estimated across-environment (control versus inoculated) covariances in bivariate analyses of flower production, and aboveground biomass. These bivariate analyses allowed for a second test for genetic variation for tolerance. These analyses test for a genotype $x$ environment interaction, and variation for tolerance would be indicated by genetic correlation coefficients significantly less than 1.0 (Lynch and Walsh, 1998). In each case, variance components estimated as 0 in the univariate analyses were constrained to 0 in the bivariate analyses. As the traits in these bivariate analyses were measured on different individuals (one measurement for each control plant and one measurement for each infected plant), we constrained the environmental covariance to 0 , except in the cost of tolerance analyses. As tolerance was calculated from both control and inoculated plants, an environmental covariance between tolerance and control performance was possible. Variance and covariance parameters were estimated for each of the remaining components of the Cockerham and Weir (1977) Bio model.

We tested for a cost of resistance by performing bivariate analyses between ELISA absorbance of infected plants and aboveground biomass and flower production of control plants. As the ELISA absorbance is a measure of virus accumulation in the host, a high ELISA absorbance is indicative of low resistance of the host to
CMV. For this and other bivariate analyses involving ELISA absorbance, the signs of the breeding values have been reversed, so that the most resistant genotypes have the highest (positive) breeding values, and the least resistant genotypes have the lowest (negative) breeding values. This produces the traditional expectation of negative genetic correlations for costs and tradeoffs involving resistance. Again, because the traits in these bivariate analyses were measured on different individuals (performance on control plant and ELISA scores on infected plants), we constrained the environmental covariance to 0 . Variance components found to be 0 in the univariate analyses also were constrained to be 0 in these bivariate analyses.

We tested for a trade-off between resistance and tolerance by performing a bivariate analysis of ELISA absorbance and tolerance. Separate bivariate analyses were run for ELISA absorbance and tolerance based on aboveground biomass and flower production.

The hypothesis that variance or covariance components differed from 0 was evaluated using log-likelihood ratio tests. In this method, the parameter estimate of interest (eg the additive genetic variance component) was constrained to 0 . Twice the difference between the log-likelihood of unconstrained and constrained models is distributed as $\chi^{2}$ with $1 \mathrm{df}$.

\section{Results}

\section{Effects of CMV on plant performance}

The large majority of M. guttatus plants inoculated with CMV developed chlorosis (74\%), and a large proportion $(33 \%)$ showed severe floral deformities with unfused petals and malformed stamens and pistils. CMV had no significant effect on DFF, but the virus significantly reduced flower production by $11.8 \%$ and aboveground biomass by $30.9 \%$. As CMV did not alter DFF, the DFF data set was not used in tests for costs of resistance or tolerance or for the tests for trade-offs between resistance and tolerance.

\section{Univariate analyses of genetic variation}

All three measures of plant performance, DFF, flower production, and aboveground biomass, showed significant additive genetic variation, with narrow-sense heritabilities ranging from 0.32 to 0.62 (Table 1). For all three, heritabilities were consistently higher for plants

Table 1 Standardized variance components $\left(s_{i}^{2} / s_{\text {total }}^{2}\right.$, where $s_{1}^{2}$ is the variance component of interest) from univariate analyses of three measures of plant performance: DFF, total flower production, and aboveground biomass

\begin{tabular}{|c|c|c|c|c|c|c|}
\hline \multirow[t]{2}{*}{ Variance component } & \multicolumn{2}{|c|}{$D F F$} & \multicolumn{2}{|c|}{ Flowers } & \multicolumn{2}{|c|}{ Biomass } \\
\hline & C & $I$ & C & $I$ & C & $I$ \\
\hline Additive & $0.57^{* * *}$ & $0.62^{* * *}$ & $0.37^{* * *}$ & $0.41^{* * *}$ & $0.32^{* * *}$ & $0.42^{* * *}$ \\
\hline Dominance & 0.09 & 0.03 & 0.00 & 0.00 & 0.00 & 0.00 \\
\hline Maternal & $0.06^{* *}$ & 0.03 & $0.06^{* *}$ & $0.04^{*}$ & $0.04^{*}$ & $0.06^{* * *}$ \\
\hline Paternal & 0.00 & 0.00 & 0.00 & 0.00 & 0.00 & 0.00 \\
\hline Interaction & $0.14^{* * *}$ & $0.18^{* * * *}$ & $0.11^{* * *}$ & $0.12^{* * *}$ & $0.09^{* * *}$ & $0.10^{* * *}$ \\
\hline Environment & 0.15 & 0.14 & 0.46 & 0.43 & 0.55 & 0.42 \\
\hline Phen. var. & 44.95 & 48.59 & 3.73 & 3.51 & 0.07 & 0.08 \\
\hline
\end{tabular}

Note that the standardized additive component is the narrow-sense heritability. Variance components are reported for Mimulus guttatus controls (C) and those plants infected with Cucumber mosaic virus (I). ${ }^{*} P<0.05,{ }^{* *} P<0.01,{ }^{* * *} P<0.001$. The total phenotypic variance (Phen. var.) is also listed. 
Table 2 Standardized variance components $\left(s_{i}^{2} / s_{\text {total }}^{2}\right)$ from univariate analyses of diallel data for ELISA absorbance and measures of tolerance (infected-control) based on date of first flower, flower production, and aboveground biomass

\begin{tabular}{lccc}
\hline $\begin{array}{l}\text { Variance } \\
\text { component }\end{array}$ & $\begin{array}{c}\text { ELISA } \\
\text { absorbance }\end{array}$ & $\begin{array}{l}\text { Tolerance } \\
\text { (flowers) }\end{array}$ & $\begin{array}{c}\text { Tolerance } \\
\text { (biomass) }\end{array}$ \\
\hline Additive & 0.027 & 0.013 & 0.015 \\
Dominance & 0.000 & 0.004 & 0.041 \\
Maternal & 0.000 & $0.020^{*}$ & 0.000 \\
Paternal & 0.006 & 0.000 & 0.002 \\
Interaction & 0.007 & 0.000 & 0.000 \\
Environment & 0.960 & 0.963 & 0.942 \\
Phen. Var. & 4.37 & 4.37 & 0.098 \\
\hline
\end{tabular}

All variance components are not significantly greater than 0 . ${ }^{*} P<0.05$. The total phenotypic variance (phen. var.) is also listed.

infected with CMV, with the heritability of aboveground biomass increasing almost $30 \%$ over the uninfected plants. This large increase as well as the increase seen in the heritability of DFF was due primarily to the expression of greater additive genetic variation (the numerator of heritability) in infected plants rather than a reduction in total phenotypic variation (the denominator of heritability). Dominance variance was not significantly greater than zero for any trait, but all showed significant interaction effects. These interactions represent nuclear $\times$ non-nuclear (eg cytoplasmic) effects. Maternal effects were significant for all traits except DFF in inoculated plants.

Unlike the individual performance traits, our univariate analyses of resistance (ELISA absorbance, which is a measure of virus accumulation) and tolerance revealed very low heritabilities, none of which were significantly greater than zero (Table 2). Dominance, paternal effects, and nuclear $\times$ non-nuclear interactions were also very small, and maternal effects were significant only for tolerance based on flower production.

\section{Genetic correlations}

The low levels of genetic variation that we observed for tolerance and resistance made it difficult to detect significant genetic correlations involving these traits, but the patterns are nonetheless informative. We tested for a cost of resistance by examining the additive genetic correlation between the performance (aboveground biomass and flower production) of control plants and the resistance of inoculated plants. There was weak evidence of a trade-off with aboveground biomass, but neither genetic correlation was significantly different from 0 (Figure 1). Interestingly, however, there were strong positive correlations in maternal effects seen in the analyses involving flower production and aboveground biomass ( $r=1.0$ in each case). These indicate that maternal effects that are favorable for performance are not favorable for resistance.

Similarly, we tested for a cost of tolerance by examining the genetic correlation between performance traits of control plants and tolerance. We found the expected negative genetic correlations between tolerance and both flower production and aboveground biomass of control plants, but neither of these correlations was significant (Figure 2).

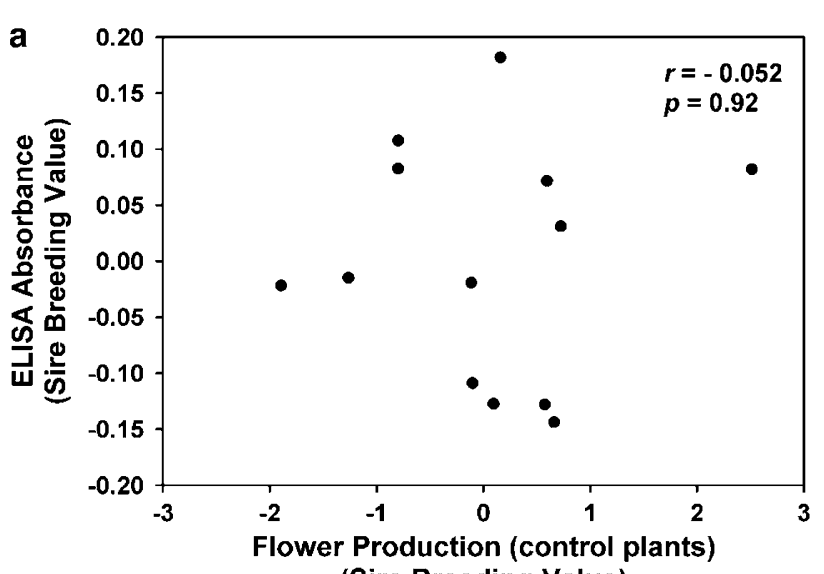

(Sire Breeding Value)

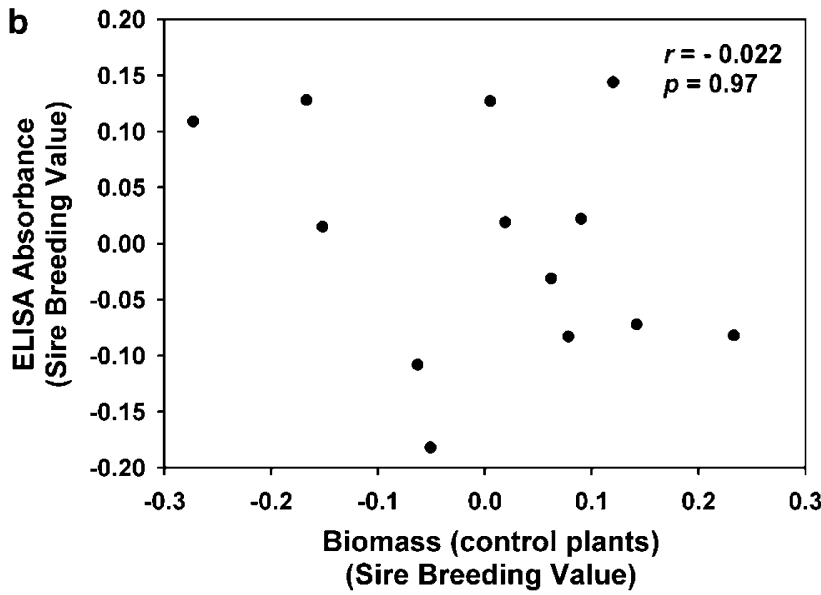

Figure 1 Genetic correlations between resistance (ELISA absorbance) and the performance of uninfected (control) plants based on (a) flower production and (b) aboveground biomass. As the breeding value signs for ELISA absorbance have been reversed, costs of resistance would be revealed by significant negative genetic correlations. The additive genetic correlations $(r)$ were estimated using the restricted maximum-likelihood estimation procedure in Quercus (Shaw, 1987; Shaw and Shaw, 1994). Sire breeding values were obtained as twice the difference between a sire's mean progeny performance and the grand mean (Falconer and MacKay, 1996). Approximate standard errors are 0.301 and 0.302 for the correlations in (a) and (b), respectively.

The additive genetic correlations between the performance (flower production and aboveground biomass) of inoculated and control plants were all significant and strongly positive (Figure 3). These data indicate that the best performers fared well with or without CMV infection and the poorer performers were poor, with or without infection. Neither of the two additive genetic correlations was significantly different from 1.0, supporting our earlier conclusion that there is little genetic variation for tolerance. Strong positive correlations were also observed in the effects of the maternal environment $(r=0.854$ and $r=1.0$ for flower production and aboveground biomass, respectively).

We tested for evidence of a trade-off between resistance and tolerance by examining their genetic correlation (Figure 4). No evidence of a trade-off was observed, with the additive genetic correlation near zero for tolerance calculated from the flower production data (Figure 4a) and positive for tolerance calculated from the 
34
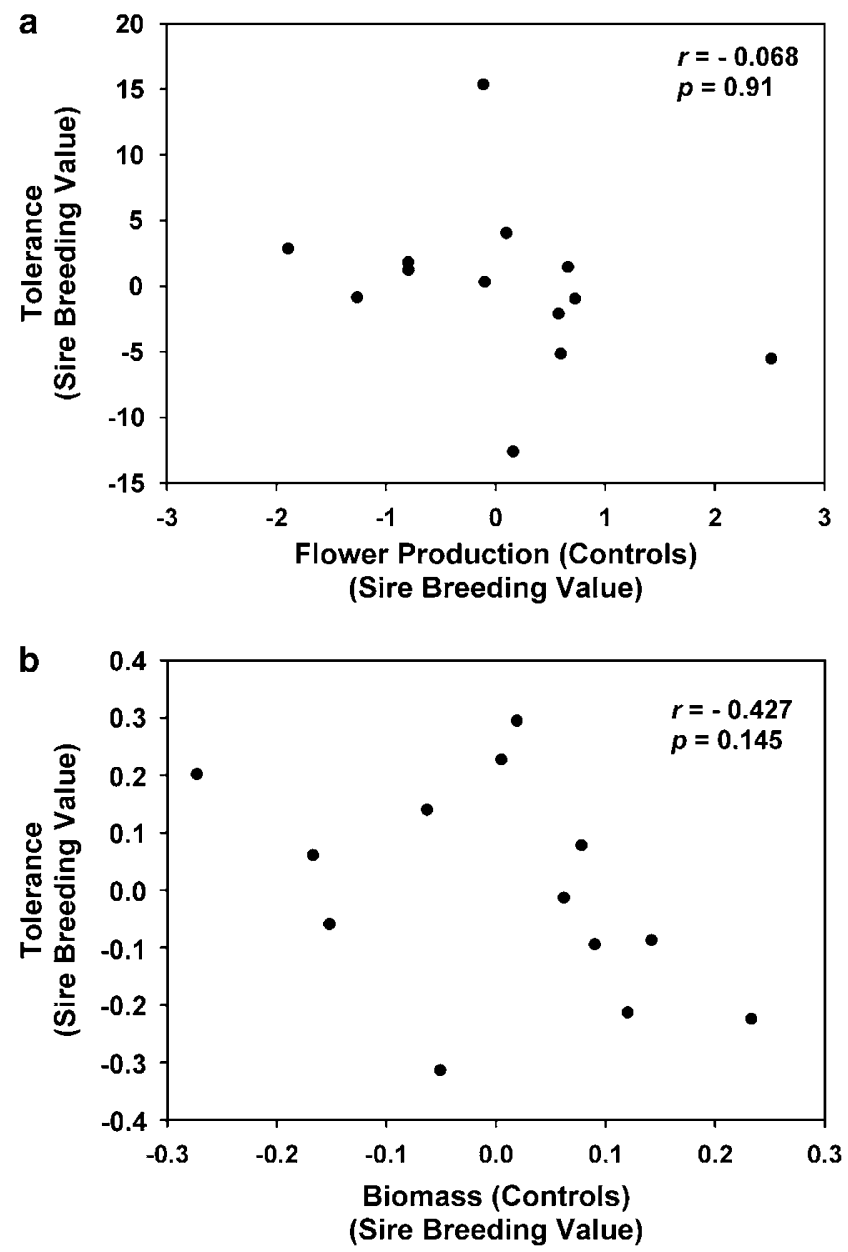

Figure 2 Genetic correlations between tolerance (inoculated plantscontrol plants) and the performance of uninfected (control) plants based on (a) flower production and (b) aboveground biomass. Additive genetic correlations and sire breeding values were obtained as in Figure 1. Approximate standard errors are 0.300 and 0.273 for correlations in (a) and (b), respectively.

aboveground biomass data (Figure 4b), indicating that the most resistant genotypes also tend to be the most tolerant. In neither case, however, is the correlation significantly different from zero.

\section{Discussion}

\section{Genetic variation for resistance and tolerance}

In a review of resistance to plant viruses in crop cultivars, Fraser (1990) noted that the genetic basis of resistance ranged from simple, single locus control to polygenic control involving modifier loci and epistasis (eg Drijfhout, 1978). In particular, work on the genetics of CMV infection in cultivars of the gourd Cucurbita pepo showed that the inheritance of resistance likely involved at least two loci with direct effects on resistance and many more loci that acted indirectly through their effects on growth rate and general vigor (Pink, 1987).

Our data on virus accumulation obtained from ELISA showed continuous, normally distributed variation, but narrow-sense heritability estimates derived from these data were low, suggesting little additive genetic variation for resistance to CMV infection in M. guttatus. Herit-
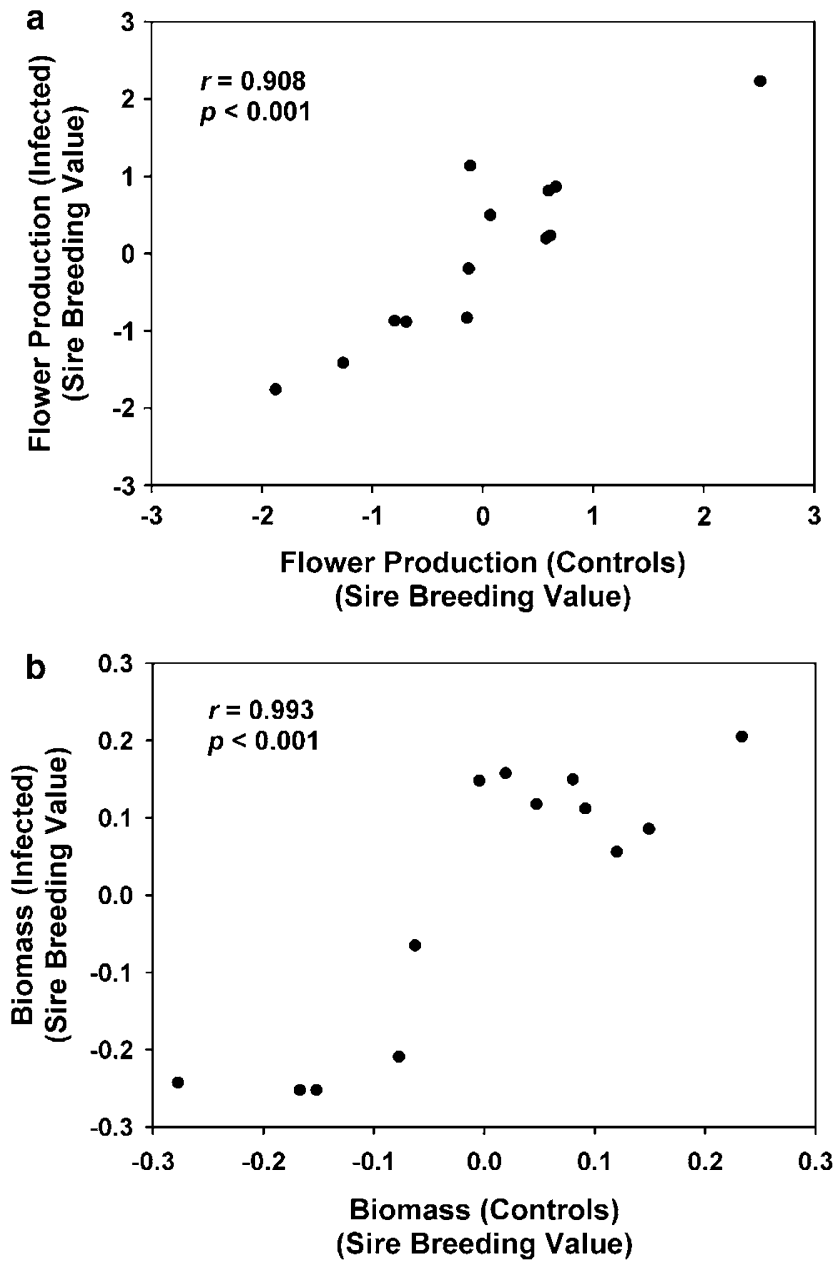

Figure 3 Genetic correlations between performance (flower production (a) and aboveground biomass, (b) of plants with and without $\mathrm{CMV}$ infection. Additive genetic correlations and sire breeding values were obtained as in Figure 1. Standard errors for correlation coefficients for flower production and aboveground biomass are approximately 0.126 and 0.036 , respectively. Confidence intervals $(95 \%)$ overlap with $r=1.0$ in both cases.

ability estimates for plant performance traits reflected a fairly high degree of additive genetic variation, comparable to levels seen in floral morphology traits in $M$. guttatus (Carr and Fenster, 1994; Robertson et al, 1994). When inoculated and control plants were compared, however, we found very low levels of additive genetic variation for tolerance. This was true whether tolerance was measured as the difference in performance between inoculated and control plants or by examination of the genetic correlation between performance of inoculated and control plants. All measures of plant performance were strongly, positively correlated across inoculated and control plants, suggesting that the most vigorous genotypes performed well, whether they were infected or not, and that the least vigorous genotypes performed poorly, whether they were infected or not.

Our observation of low levels of additive genetic variation for tolerance is consistent with a model presented by Roy and Kirchner (2000) that predicts low levels of variation for tolerance to pathogens. If an allele confers greater tolerance to a pathogen, it will be favored by natural selection. As tolerance spreads through the 

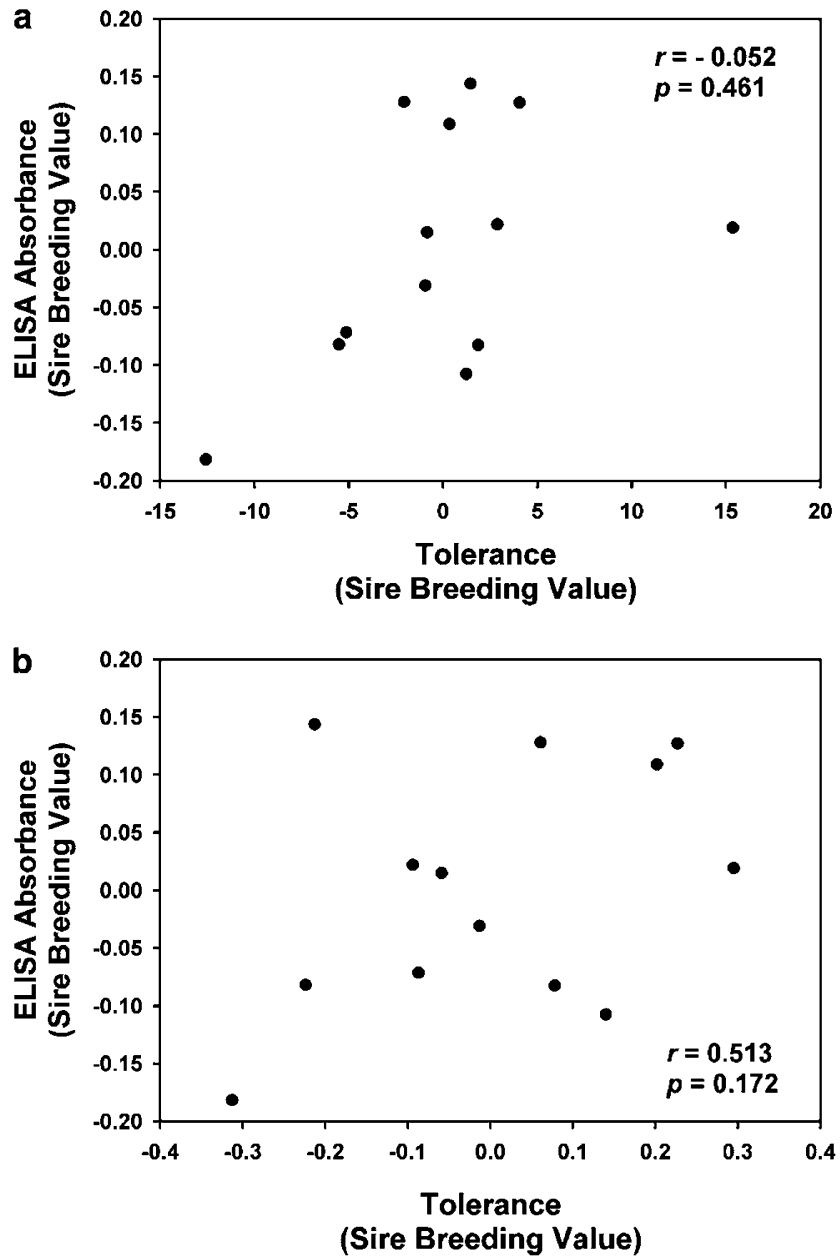

Figure 4 Genetic correlations between resistance (ELISA absorbance) and tolerance (inoculated plants-control plants) based on flower production (a) and aboveground biomass (b). A trade-off would be revealed as a negative correlation. Additive genetic correlations and sire breeding values were obtained as in Figure 1. Approximate standard errors for (a) and (b) are 0.301 and 0.258, respectively.

population, the pathogen should become more common because this indirectly selects for susceptible genotypes. As the pathogen becomes more common, selection for tolerance becomes intensified, and the positive feedback quickly drives the allele to fixation. Roy and Kirchner (2000) cite 11 studies on plant-rust interactions that conform to their predictions of low levels of variation for tolerance. Their model assumes no cost to tolerance, however, and does not consider evolutionary responses of the pathogen, which may increase in virulence as tolerance evolves in the host (Desbiez et al, 2003).

The low levels of variation for resistance found in $M$. guttatus were more surprising. Genetic variation for resistance to pathogens is commonly found in natural plant populations (eg Morrison, 1996; Thrall et al, 2001; Chiang et al, 2002; Koskela et al, 2002; Liu and Ekramoddoullah, 2003), although it is not universal (eg Simms and Triplett, 1994). There are several factors that should act to maintain genetic variation for resistance. Roy and Kirchner (2000) point out that genetic variation for resistance should be maintained under most conditions because the selective advantage of a resistance allele should be negatively frequency dependent. The allele has its greatest advantage when rare because the pathogen should be common, but the advantage decreases as the allele spreads through the population and the pathogen consequently becomes less common. Spatial structure of the host population should also help maintain genetic variation for resistance (Thrall and Burdon, 2002), as should a cost of resistance (Frank, 1992, 1994). Genetic variation in the pathogen could result in frequency-dependent selection, leading to high levels of genetic variation in the host, especially if resistance has a high specificity (eg Hamilton et al, 1990). We suggest that M. guttatus may cope with a generalist virus like CMV by continuing to grow and develop despite the infection and drain on resources.

Nuclear $\times$ non-nuclear interactions were evident for all performance traits, accounting for as much as $18 \%$ of phenotypic variation (Table 1). Such interactions are often observed in crosses between populations, but are surprising to find in crosses made within populations, as in our case (Clark and Lyckegaard, 1988). Combined direct and indirect (interaction) maternal effects accounted for as much as $21 \%$ of phenotypic variation. These effects would have the effect of slowing the response to selection in a random-mating population. Maternal effects generally increased plant performance.

\section{Cost of resistance and tolerance}

In order to account for the existence of genetic variation for resistance, many models of the evolution of resistance to pathogens assume that a cost of resistance exists (Leonard and Czochor, 1980; Antonovics and Thrall, 1994). If there is no cost to tolerance or resistance, many theoretical models predict that alleles that increase tolerance to natural enemies should quickly sweep to fixation (Roy and Kirchner, 2000; Tiffin, 2000). We found no evidence of significant costs of resistance or tolerance. On the contrary, those genotypes that displayed the highest levels of tolerance when infected with CMV tended to have the highest aboveground biomass when uninfected.

Costs of resistance have been reported in prior studies of plant-pathogen systems, although cost is not universally found. In S. alba, Biere and Antonovics (1996) found gender-specific costs of resistance to anther smut fungus, Microbotryum violaceum. In populations without the fungus, highly resistant male $S$. alba genotypes had lower reproductive success than highly susceptible genotypes. Female $S$. alba exhibited no cost of resistance. In an artificial selection study of the mustard Brassica rapa, Mitchell-Olds (1996) found a strong cost of resistance to the fungus Peronospora parasitica but no cost of resistance to the fungus Leptosphaeria maculans. On the other hand, Simms and Triplett (1994) found that Ipomoea purpurea genotypes that were most resistant to the fungal pathogen Colletotrichum dematium also performed the best in disease-free environments.

Costs of tolerance to anthracnose have been observed in I. purpurea (Simms and Triplett, 1994), and the reduced competitive ability of grazing-adapted plants suggests that costs may be common in plant-herbivore systems (Painter et al, 1989). We observed no evidence for a cost of tolerance. The strong positive correlations between performance of infected and uninfected genotypes 
suggest that costs, if any, are minimal. This suggests that selection operating in M. guttatus populations should favor the same genotypes whether those populations are infected with CMV or not.

In our analyses of potential costs of resistance, we uncovered very strong, positive maternal effect correlations between our measures of control plant performance and our measure of virus accumulation. This result clearly illustrates the potential errors in interpretation that can be caused by genetic analyses that fail to factor out maternal effects (eg analyses relying simply on family means; Falconer and MacKay, 1996). In analyses that confound maternal effects with genetic effects, the maternal effects observed in this study would likely have been misinterpreted as evidence for costs of resistance when, in fact, none appear to exist.

\section{Trade-off between resistance and tolerance}

Tolerance and resistance may represent alternative state solutions to the selective force imposed by natural enemies (Strauss and Agrawal, 1999). Highly resistant genotypes will experience little selection for increased tolerance, and highly tolerant genotypes should experience little selection for resistance. Resistance and tolerance to herbivores have indeed been found to show negative genetic correlation within populations (Fineblum and Rausher, 1995; Fornoni et al, 2003). We have found no evidence for such a trade-off between resistance and tolerance to $\mathrm{CMV}$, nor do we know of any published evidence for pathogen defense in general. If any correlation did exist, our data suggest that resistance and tolerance to CMV appear to be positively correlated in M. guttatus. As discussed earlier, this pattern may be due to the ability of the most vigorous plants to essentially outgrow the damage caused by CMV infection.

A difficulty in evaluating tolerance by simply comparing infected and control plants is that tolerance and resistance are somewhat confounded in an experiment of this kind. The damage observed in any infected plant relative to its control is potentially a function of the severity of its infection as well as any physiological or developmental ability to tolerate infection. If all plants were equally physiologically and developmentally tolerant but variable in resistance, a positive correlation would be observed between 'tolerance' (as we have measured it in this experiment) and resistance. Resistant plants with low-level infections would exhibit little performance difference (apparent 'high tolerance'), whereas less resistant plants would exhibit high levels of damage (apparent 'low tolerance'). This would produce the pattern we observed in the correlations between performance and ELISA absorbance. Without a measure of tissue or physiological damage caused by the pathogen, it would be premature to completely reject the trade-off hypothesis for resistance and tolerance. An alternative approach would be to measure tolerance as the slope of the regression line of performance on infection level.

\section{Conclusions}

Despite fairly high levels of genetic variation for performance traits, $M$. guttatus exhibits little genetic variation for resistance or tolerance to the generalist pathogen CMV. Evidence for a cost of resistance or tolerance was absent. The hypothesized trade-off between resistance and tolerance was also unsupported, with the observed correlation opposite in sign to the expectation. The evolution of tolerance and resistance in this system appears constrained primarily by low levels of genetic variation. Our data demonstrate strong positive genetic correlations between the performance of uninfected and infected plants, suggesting that in this interaction between a generalist pathogen and an annual plant, CMV infection would not alter the pattern of selection.

\section{Acknowledgements}

Peter Palukautis provided the CMV strain used in this experiment. Zandra DeLamar helped with data entry. Christopher Ivey and Ruth Shaw provided important advice on the analyses. This work was supported by National Science Foundation Grants DEB-0075225 to DEC, DEB-0074556 to MDE, and NSF BIR-9512202 to MA Bowers and E Connor, a University of Virginia FEST grant to DEC, the Blandy Experimental Farm, and the Department of Entomology and Plant Pathology at Auburn University.

\section{References}

Alexander HM, Antonovics J (1995). Spread of anther-smut disease (Ustilago violacea) and character correlations in a genetically variable experimental population of Silene alba. J Ecol 83: 783-794.

Antonovics J, Thrall PH (1994). The cost of resistance and maintenance of genetic polymorphism in host-pathogen systems. Proc R Soc Lond Ser B 257: 105-110.

Beardsley PM, Olmstead RG (2002). Redefining the Phrymaceae: the placement of Mimulus, tribe Mimuleae and Phryma. Am J Bot 89: 1093-1102.

Biere A, Antonovics J (1996). Sex-specific costs of resistance to the fungal pathogen Ustilago violacea (Microbotryum violaceum) in Silene alba. Evolution 50: 1098-1110.

Brunt AA, Crabtree K, Dallwitz MJ, Gibb AJ, Watson L, Zurcher EJ (1996). Plant viruses online: descriptions and lists from the VIDE Database, Version 20. Published electronically on the internet from http://image.fs.uidaho.edu/vide/refs.htm

Carr DE, Eubanks MD (2002). Inbreeding alters resistance to insect herbivory and host plant quality in Mimulus guttatus (Scrophulariaceae). Evolution 17: 85-103.

Carr DE, Fenster CB (1994). Levels of genetic variation and covariation for Mimulus (Scrophulariaceae) floral traits. Heredity 72: 606-618.

Carr DE, Murphy JF, Eubanks MD (2003). The susceptibility and response of inbred and outbred Mimulus guttatus to infection by Cucumber mosaic virus. Evol Ecol 17: 85-103.

Chiang YC, Ge XJ, Chou CH, Wu WL, Chiang TY (2002). Nucleotide sequence diversity at the methionine synthase locus in endangered Dunnia sinensis (Rubiaceae): an evaluation of the positive selection hypothesis. Mol Biol Evol 19: 1367-1375.

Clark AG, Lyckegaard EMS (1988). Natural selection with nuclear and cytoplasmic transmission. III. Joint analysis of segregation and mtDNA in Drosophila melanogaster. Genetics 118: 471-481.

Cockerham CC, Weir BS (1977). Quadratic analyses of reciprocal crosses. Biometrics 33: 187-203.

Davelos AL, Alexander HM, Slade NA (1996). Ecological genetic interactions between a clonal host plant (Spartina 
pectinata) and associated rust fungi (Puccinia seymouriana and Puccinia sparganioides). Oecologia 105: 205-213.

Dawson WO, Hilf ME (1992). Host range determinants of plant viruses. Annu Rev Plant Phys Plant Mol Biol 43: 527-555.

Desbiez C, Gal-On A, Girard M, Wipf-Scheibel C, Lecoq H (2003). Increase in zucchini yellow mosaic virus symptom severity in tolerant zucchini cultivars is related to a point mutation in P3 protein and is associated with a loss of relative fitness on susceptible plants. Phytopathology 93: 1478-1484.

Dole JA (1992). Reproductive assurance mechanisms in three taxa of the Mimulus guttatus complex (Scrophulariaceae). Am J Bot 79: 650-659.

Drijfhout E (1978). Genetic interaction between Phaseolus vulgaris and bean common mosaic virus with implications for stain identification and breeding for resistance. Agricultural Research Report, Wagening No. 872.

Dudash MR, Ritland K (1991). Multiple paternity and selffertilization in relation to floral age in Mimulus guttatus (Scrophulariaceae). Am J Bot 78: 1746-1753.

Edwardson JR, Christie RG (1991). CRC Handbook of Viruses Affecting Legumes. CRC Press Inc.: Boca Raton, FL, USA.

Ellis J, Dodds P, Pryor T (2000). The generation of plant disease resistance gene specificities. Trends Plant Sci 5: 373-379.

Eubanks MD, Carr DE, Murphy JF (2004). Variation in the response of Mimulus guttatus (Scrophulariaceae) to herbivore and virus attack. Evol Ecol 18 (in press).

Falconer DS, MacKay TFC (1996). Introduction to Quantitative Genetics, 4th edn. Longman: Essex, England.

Fineblum WL, Rausher MD (1995). Tradeoff between resistance and tolerance to herbivore damage in a morning glory. Nature 377: 517-520.

Fineblum WL, Rausher MD (2002). Tradeoff between resistance and tolerance to herbivore damage in a morning glory. Nature 377: 517-520.

Fornoni J, Valverde PL, Núñez-Farfán J (2003). Quantitative genetics of plant tolerance and resistance against natural enemies of two natural populations of Datura stramonium. Evol Ecol Res 5: 1049-1065.

Frank SA (1992). Models of plant-pathogen coevolution. Trends Genet 8: 213-219.

Frank SA (1994). Coevolutionary genetics of hosts and parasites with quantitative inheritance. Evol Ecol 8: 74-94.

Fraser RSS (1990). The genetics of resistance to plant viruses. Annu Rev Phytopathol 28: 179-200.

Gilbert GS (2002). Evolutionary ecology of plant diseases in natural ecosystems. Annu Rev Phytopathol 40: 13-43.

Guerini MN, Murphy JF (1999). Resistance of Capsicum annuum 'Avelar' to pepper mottle potyvirus and alleviation of this resistance by co-infection with cucumber mosaic cucumovirus are associated with virus movement. I Gen Virol 80: 2785-2793.

Hamilton WD, Axelrod R, Tanese R (1990). Sexual reproduction as an adaptation to resist parasites (a review). Proc Natl Acad Sci USA 87: 3566-3573.

Harper JL (1977). The Population Biology of Plants. Academic Press: London.

Hull R (2002). Matthews' Plant Virology, 4th edn. Academic Press Publishers: San Diego, CA.

Jarosz AM, Burdon JJ (1991). Host-pathogen interactions in natural populations of Linum marginale and Melampsora lini: II. Local and regional variation in patterns of resistance and spatial structure. Evolution 45: 1618-1627.

Koskela T, Puustinen S, Salonen V, Mutikainen P (2002). Resistance and tolerance in a host plant-holoparasitic plant interaction: genetic variation and costs. Evolution 56: 899-908.

Kover PX, Schaal BA (2002). Genetic variation for disease resistance and tolerance among Arabidopsis thaliana accessions. Proc Natl Acad Sci USA 99: 11270-11274.
Leonard KJ, Czochor RJ (1980). Theory of genetic interactions among populations of plants and their pathogens. Annu Rev Phytopathol 18: 237-258.

Liu JJ, Ekramoddoullah AKM (2003). Isolation, genetic variation and expression of TIR-NBS-LRR resistance gene analogs from western pine (Pinus monticola Dougl. Ex. D. Don.). Mol Genet Genomics 270: 432-441.

Lynch M, Walsh B (1998). Genetics and Analysis of Quantitative Traits. Sinauer Associates: Sunderland, MA.

Mauricio R, Rausher MD, Burdick DS (1997). Variation in the defense strategies of plants: are resistance and tolerance mutually exclusive? Ecology 78: 1301-1311.

Mitchell-Olds T (1996). Pleiotropy causes long-term genetic constraints on life-history evolution in Brassica rapa. Evolution 50: $1849-1858$.

Morrison JA (1996). Infection of Juncus dichotomus by the smut fungus Cintractia junci: an experimental field test of the effects of neighboring plants, environment, and host plant genotype. J Ecol 84: 691-702.

Murphy JF, Blauth JR, Livingstone KD, Lackney V, Jahn MK (1998). Genetic mapping of the pvr1 locus in Capsicum spp. and evidence that distinct potyvirus resistance loci control responses to two potyviruses that differ at the whole plant and cellular levels. Mol Plant-Microbe Interactions 11: 943-951.

Murphy JF, Kyle M (1995). Alleviation of restricted systemic spread of pepper mottle potyvirus in Capsicum annuum cv. avelar by coinfection with a cucumovirus. Phytopathology 85 : 561-566.

Ouborg NJ, Biere A, Muddle CL (2000). Inbreeding effects on resistance and transmission-related traits in the SileneMicrobotryum pathosystem. Ecology 81: 520-531.

Painter EL, Detling JK, Steingraeber DA (1989). Grazing history, defoliation, and frequency-dependent competition: effects on two North American grasses. Am J Bot 76: 1368-1379.

Palukaitis P, Roossink MJ, Dietzgen RG, Francki RIB (1992). Cucumber mosaic virus. Adv Virus Res 41: 281-348.

Pink DAC (1987). Genetic control of resistance to cucumber mosaic virus in Cucurbita pepo. Ann Appl Biol 111: 425-432.

Ponz F, Bruening G (1986). Mechanisms of resistance to plantviruses. Annu Rev Phytopathol 24: 355-381.

Restif O, Koella JC (2004). Concurrent evolution of resistance and tolerance to pathogens. Am Nat 164: E90-E102.

Ritland K (1990). Inferences about inbreeding depression based on changes of the inbreeding coefficient. Evolution 44 1230-1241.

Ritland K, Ritland C (1989). Variation of sex allocation among eight taxa of the Mimulus guttatus species complex (Scrophulariaceae). Am J Bot 76: 1731-1739.

Robertson AW, Diaz A, Macnair MR (1994). Quantitative genetics of floral characters in Mimulus guttatus. Heredity 72: 300-311

Roy BA, Kirchner JW (2000). Evolutionary dynamics of pathogen resistance and tolerance. Evolution 54: 51-63.

Schmid B (1994). Effects of genetic diversity in experimental stands of Solidago altissima - evidence for the potential role of pathogens as selective agents in plant populations. J Ecol 82: 165-175.

Shaw R (1987). Maximum-likelihood approaches to quantitative genetics of natural populations. Evolution 41: 812-826.

Shaw RG, Shaw FH (1994). Quercus: programs for quantitative genetic analysis using maximum likelihood. Published electronically on the Internet from http://www.cbs.umn. edu/eeb/events/quercus.shtml.

Sheldon BC, Verhulst S (1996). Ecological immunology: costly parasite defenses and trade-offs in evolutionary ecology. Trends Ecol Evol 11: 317-321.

Simms EL, Triplett J (1994). Costs and benefits of plant responses to disease: resistance and tolerance. Evolution 48 1973-1985. 
Stowe KA (1998). Experimental evolution of resistance in Brassica rapa: correlated response in tolerance in lines selected for glucosinolate content. Evolution 52: 703-712.

Strauss SY, Agrawal AA (1999). The ecology and evolution of plant tolerance to herbivory. Trends Ecol Evol 14: 179-185.

Thrall PH, Burdon JJ (2000). Effect of resistance variation in a natural host-pathogen metapopulation on disease dynamics. Plant Pathol 49: 767-773.

Thrall PH, Burdon JJ (2002). Evolution of gene-for-gene systems in metapopulations: the effect of spatial scale of host and pathogen dispersal. Plant Pathol 51: 169-184.
Thrall PH, Burdon JJ, Young A (2001). Variation in resistance and virulence among demes of a plant host-pathogen metapopulation. J Ecol 89: 736-748.

Tiffin P (2000). Are tolerance, avoidance, and antibiosis evolutionarily and ecologically equivalent responses to plant herbivores? Am Nat 155: 128-138.

van der Meijden E, Wijn H, Verkaar J (1988). Defence and regrowth: alternative plant strategies in the struggle against herbivores. Oikos 51: 355-363.

Willis JH (1993). Partial self-fertilization and inbreeding depression in two populations of Mimulus guttatus. Heredity 71: $145-154$ 